\title{
Combined laparoscopic and thoracoscopic surgical repair of Bochdalek hernia in an adult: a case report
}

\author{
Sho Nambara ${ }^{1 *} \mathbb{0}$, Yoshihisa Sakaguchi ${ }^{1}$, Fumihiro Shoji ${ }^{2}$, Yasuo Tsuda ${ }^{1}, K^{\prime}$ Kensuke Kudou' ${ }^{1}$ Eiji Kusumoto ${ }^{1}$, \\ Kenkichi Hashimoto ${ }^{1}$, Tetsuya Kusumoto ${ }^{1}$ and Koji Ikejiri ${ }^{1}$
}

\begin{abstract}
Background: Bochdalek hernia is a rare disease in adults. Diaphragmatic hernia in adults has been repaired using minimally invasive surgery through laparoscopy or thoracoscopy. However, the literature regarding the combined use of laparoscopy and thoracoscopy for the repair of Bochdalek hernia is limited.

Case presentation: A 26-year-old man diagnosed with Bochdalek hernia was managed through combined abdominal and thoracic endoscopic surgery. On laparoscopy, the omentum prolapsed into the left thoracic cavity through the posterolateral area of the left diaphragm. On thoracoscopy, no adhesions of the omentum were seen in the thoracic cavity. The omentum was drawn back to the abdominal cavity, and a $4 \times 3-\mathrm{cm}$ hernial orifice was identified. The hernia orifice was repaired through simple closure with sutures laparoscopically. The patient's postoperative course was uneventful with no recurrences within the first year post-surgery.
\end{abstract}

Conclusion: Combined laparoscopic and thoracoscopic surgery is a safe and effective method for Bochdalek hernial repair in adults.

Keywords: Bochdalek hernia, Laparoscopy, Thoracoscopy

\section{Background}

Congenital posterolateral diaphragmatic hernia, also known as Bochdalek hernia, is a rare condition that primarily presents as a life-threatening cardiopulmonary disorder in the neonatal period. However, this may occasionally remain silent until adulthood, which may incidentally found by routine radiologic investigations [1-3].

Surgical repair of the hernial orifice is the definitive treatment for diaphragmatic hernia. This is warranted even in asymptomatic patients to prevent the risk of visceral herniation and strangulation. Depending on the patient's characteristics, several approaches (e.g.,

\footnotetext{
*Correspondence: nanbara36@gmail.com

${ }^{1}$ Department of Gastroenterological Surgery and Clinical Research Institute Cancer Research Division, National Kyushu Medical Center, 1-8-1 Jigyouhama Chuo-ku, Fukuoka 810-8563, Japan

Full list of author information is available at the end of the article
}

laparotomy, thoracotomy, or a combination of these) may be selected. Currently, diaphragmatic hernia has been repaired through laparoscopy or thoracoscopy with or without mesh reinforcement $[4,5]$. To the best of our knowledge, reports concerning combined laparoscopic and thoracoscopic surgery for diaphragmatic hernia are greatly limited. Here, we report a case of Bochdalek hernia in an adult repaired through combined laparoscopic and thoracoscopic surgery.

\section{Case presentation}

A 26-year-old man with unremarkable medical history presented with an abnormal shadow on routine chest radiography (Fig. 1a). Computed tomography (CT) showed herniation of a large volume of the omentum to the left thoracic cavity through an orifice in the left dorsal 


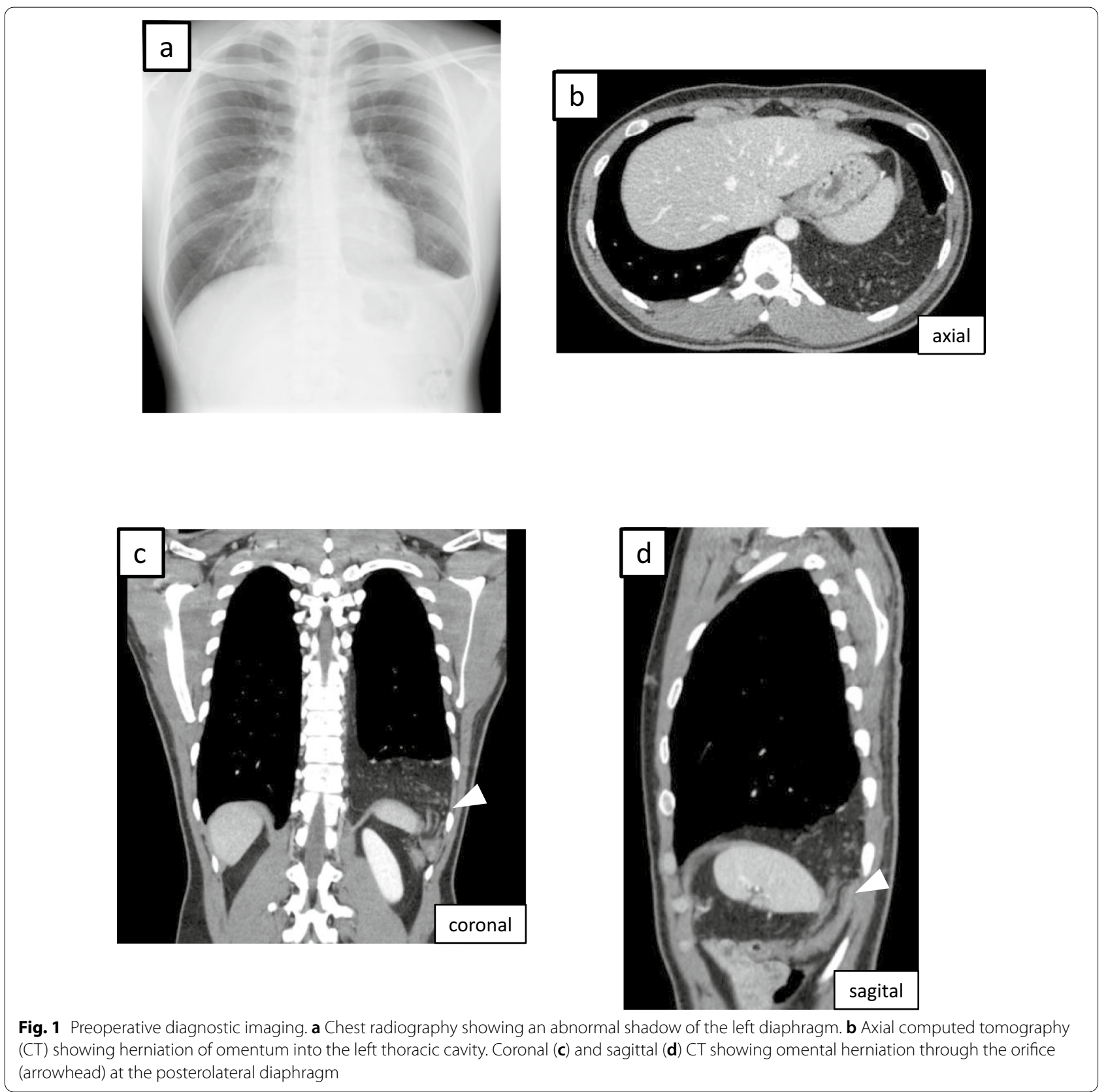

diaphragm (Fig. 1b-d). This was consistent with a diagnosis of Bochdalek hernia.

Despite being asymptomatic, the risk of incarceration of the prolapsed organs still exists. Hence, hernial repair was planned. A combined laparoscopic and thoracoscopic approach was preoperatively selected due to the large volume of the prolapsed omentum and the possibility of adhesion to the left thoracic cavity.

During the surgery, the patient was placed in the right semi-lateral position. Four trocars were placed: (1) one $12-\mathrm{mm}$ trocar at the navel, (2) one $12-\mathrm{mm}$ trocar at the left abdomen, (3) one 5- $\mathrm{mm}$ trocar at the epigastric region, and (4) one 5-mm trocar at the left 7 th intercostal space mid-axillary line (Fig. 2a). The pressure in the abdominal and thoracic cavities was maintained at $10 \mathrm{mmHg}$. On laparoscopy, the omentum prolapsed into the left thoracic cavity through the hernial orifice at the dorsolateral diaphragm (Fig. 2b). On thoracoscopy, there was no adhesion seen on the omentum in the thoracic cavity and the hernial sac (Fig. 2c).

The omentum was laparoscopically drawn out from the thorax to the abdominal cavity with simultaneous 

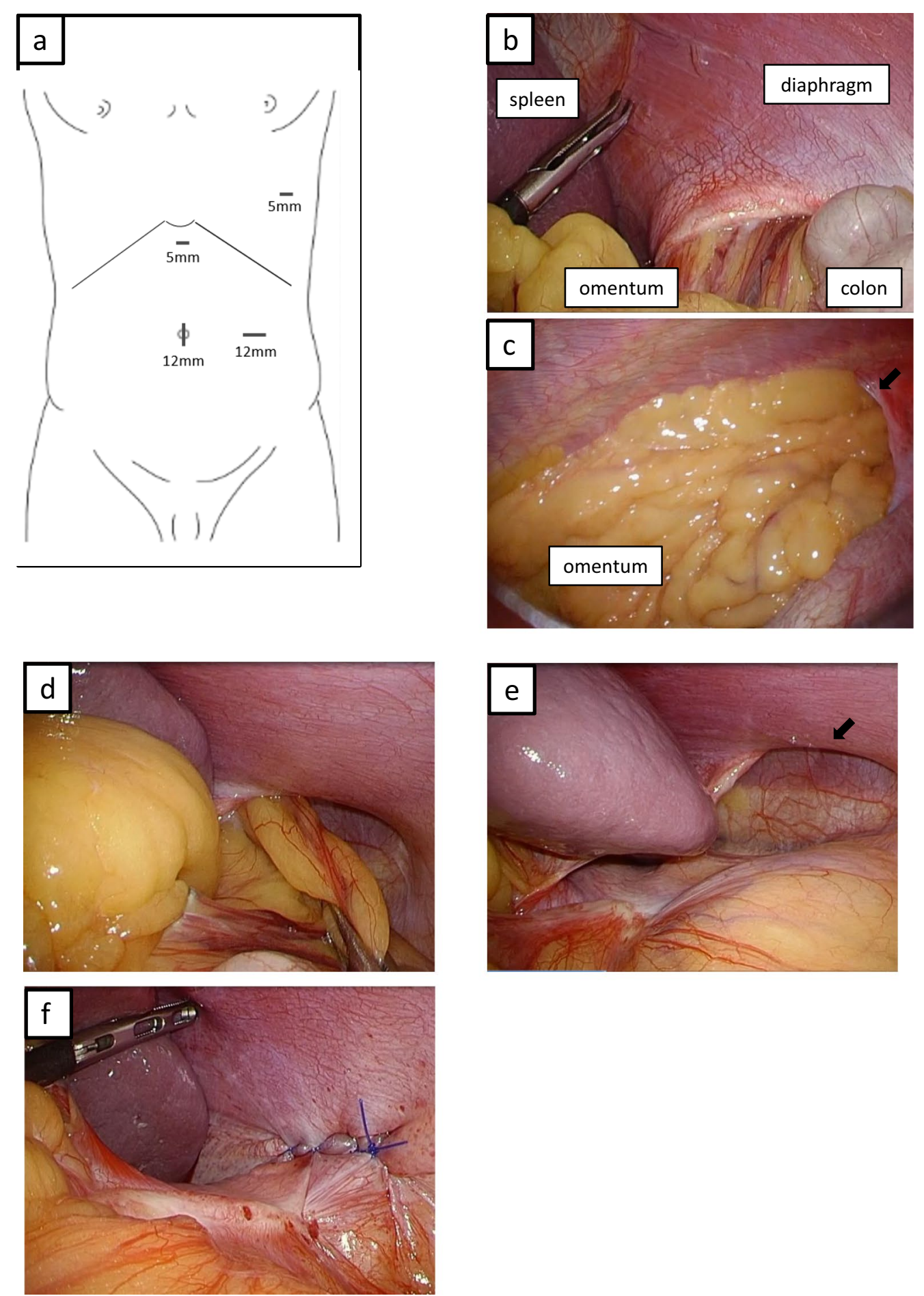

Fig. 2 Intraoperative findings. a Ports placement. b Laparoscopy showing the orifice at the posterolateral left diaphragm with herniation of the omentum. c Thoracoscopy showing the hernial orifice at the posterolateral portion of the left diaphragm (arrow) and the omentum prolapsed into the thoracic cavity. $\mathbf{d}$ Drawn out omentum into the abdominal cavity. e A $4 \times 3-\mathrm{cm}$ hernia orifice (arrow). f Diaphragmatic orifice closed using direct sutures 


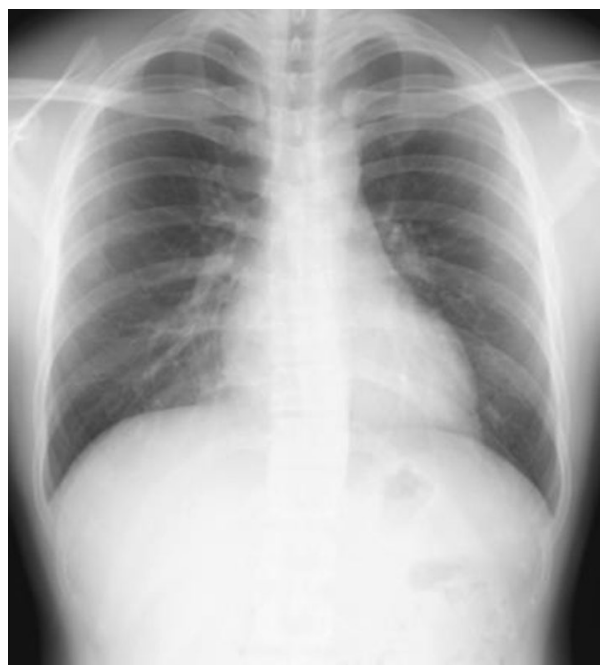

Fig. 3 Postoperative chest radiograph 1 year after surgery

observation by thoracoscopy (Fig. 2d). The hernial orifice was estimated to be $4 \times 3 \mathrm{~cm}$ in size (Fig. 2e). After moving the omentum, the orifice was laparoscopically closed by direct sutures using 3-0 V-Loc (Covidien, Mansfield, MA, USA) and 2-0 Prolene for reinforcement (Ethicon, Somerville, NJ, USA) (Fig. 2f). The intraperitoneal pressure was reduced to $5 \mathrm{mmHg}$ and there was no air leakage found from the sutured part. A 16-Fr chest drain was inserted via the left 7th intercostal space mid-axillary line. The operating time was $66 \mathrm{~min}$ and the total blood loss was $1 \mathrm{~g}$. The postoperative course was uneventful and the patient was discharged on the 6th day after surgery. No recurrence was observed one year after the surgery (Fig. 3).

\section{Discussion}

Vincent Alexander Bochdalek first described a congenital hernia resulting from the developmental failure of the diaphragmatic posterolateral foramina to fuse properly [6-8]. Bochdalek hernia is one of the most common abnormalities in infants with a reported incidence of approximately 1 in 3000 live births and represents approximately $80 \%$ of congenital diaphragmatic hernias [9]. This condition is usually diagnosed during infancy, which may present with signs and symptoms of cardiopulmonary insufficiency secondary to herniation of abdominal contents through the diaphragmatic defect.

In adults, Bochdalek hernia is considered extremely rare [1-3] and usually presents with vague and nonspecific symptoms. The common presenting symptoms include chest pain, dyspnea, gastrointestinal bleeding, and abdominal pain [3]. In our case, he presented with none of these symptoms.
The diagnosis of diaphragmatic hernia in adults is usually established through radiologic investigations [10] such as chest radiography or barium studies. CT is the most accurate imaging modality for the diagnosis and evaluation of hernia [11, 12]. In about $80 \%$ of cases, Bochdalek hernia predominantly occurs on the left hemithorax because the right pleuroperitoneal canal closes earlier than the left [6]. In our case, the patient was initially suspected to have pleurisy based on the chest radiograph. However, due to the presence of the diaphragmatic defect on the left posterolateral area as seen in CT, a diagnosis of Bochdalek diaphragmatic hernia was made.

The conventional treatment of diaphragmatic hernia involves placing the herniated organs back to the abdominal cavity and closing the diaphragmatic defect using sutures [13, 14]. Although surgical procedures for these hernias may be performed with laparotomy, thoracotomy, or a combination of both, minimally invasive approaches (e.g., laparoscopy or thoracoscopy) have recently been approved $[4,5]$. Laparoscopic surgery may allow an easier and safer return of the herniated organs back to the abdominal cavity and may provide a better examination of the whole abdominal cavity than thoracoscopic surgery [15]. In contrast, thoracoscopic surgery permits easier dissection of adhesion in the thoracic cavity than laparoscopic surgery [16]. In our case, because of the large volume of herniated omentum and the possibility of adhesion to the thoracic wall, combined laparoscopic and thoracoscopic surgery was planned to reverse the herniation and repair the orifice. Although reports of combined laparoscopic and thoracoscopic surgery exist, these were emergency operations or involved the intraoperative addition of either approach [17]. A strength of our case was that we planned combined surgery from the beginning and performed the surgery safely.

Hernial sacs have been reported to occur in $10-38 \%$ of cases [18]. In our case, no hernial sac was seen.

The hernial orifice can be closed using different methods. For cases where the defect is small, the orifice can be sutured and closed. On the other hand, for cases with large orifices ( $>10 \mathrm{~cm}$ in diameter), mesh reinforcement may be warranted $[15,19]$. As our patient's hernial orifice was less than $10 \mathrm{~cm}$ in diameter, simple closure was performed with sutures. Nonetheless, there was no recurrence in the year following surgery.

\section{Conclusion}

We have highlighted the utility of combined laparoscopic and thoracoscopic surgery for the safe and effective repair of Bochdalek hernia in adults.

Abbreviations

CT: Computed tomography. 


\section{Acknowledgements \\ Not applicable.}

\section{Authors' contributions}

All authors attest that they meet the criteria for authorship. All authors read and approved the final manuscript.

\section{Funding}

This study was not funded.

\section{Availability of data and materials}

All data generated or analyzed during this study are included in this published article.

\section{Declarations}

\section{Ethics approval and consent to participate}

Written informed consent was obtained from the patient for publication of this case report and any accompanying images.

\section{Consent for publication}

Written informed consent was obtained from the patient for publication of this case report and any accompanying images.

\section{Competing interests}

No potential conflicts of interest were disclosed.

\section{Author details}

${ }^{1}$ Department of Gastroenterological Surgery and Clinical Research Institute Cancer Research Division, National Kyushu Medical Center, 1-8-1 Jigyouhama Chuo-ku, Fukuoka 810-8563, Japan. ²Department of Thoracic Surgery, National Kyushu Medical Center, 1-8-1 Jigyohama Chuo-ku, Fukuoka 810-8563, Japan.

Received: 12 March 2021 Accepted: 9 September 2021

Published online: 21 September 2021

\section{References}

1. Bujanda L, Larrucea I, Ramos F, Muñoz C, Sánchez A, Fernández I. Bochdalek's hernia in adults. J Clin Gastroenterol. 2001;32:155-7.

2. Rout S, Foo FJ, Hayden JD, Guthrie A, Smith AM. Right-sided Bochdalek hernia obstructing in an adult: case report and review of the literature. Hernia. 2007:11:359-62.

3. Brown SR, Horton JD, Trivette E, Hofmann LJ, Johnson JM. Bochdalek hernia in the adult: demographics, presentation, and surgical management [Presentation]. Hernia. 2011;15:23-30.
4. Al-Emadi M, Helmy I, Nada MA, Al-Jaber H. Laparoscopic repair of Bochdalek hernia in an adult. Surg Laparosc Endosc Percutan Tech. 1999:9:423-5.

5. Yamaguchi M, Kuwano H, Hashizume M, Sugio K, Sugimachi K, Hyoudou Y. Thoracoscopic treatment of Bochdalek hernia in the adult: report of a case. Ann Thorac Cardiovasc Surg. 2002;8:106-8.

6. Kardon G, Ackerman KG, McCulley DJ, Shen Y, Wynn J, Shang L, et al. Congenital diaphragmatic hernias: from genes to mechanisms to therapies. Dis Models Mech. 2017;10:955-70.

7. Korom S, Canyurt H, Missbach A, Schneiter D, Kurrer MO, Haller U, et al. Catamenial pneumothorax revisited: clinical approach and systematic review of the literature. J Thorac Cardiovasc Surg. 2004;128:502-8.

8. Golombek SG. The history of congenital diaphragmatic hernia from 1850 s to the present. J Perinatol. 2002:22:242-6.

9. Stege G, Fenton A, Jaffray B. Nihilism in the 1990s: the true mortality of congenital diaphragmatic hernia. Pediatrics. 2003;112:532-5.

10. Raymond GS, Miller RM, Müller NL, Logan PM. Congenital thoracic lesions that mimic neoplastic disease on chest radiographs of adults. AJR Am J Roentgenol. 1997;168:763-9.

11. Shin MS, Mulligan SA, Baxley WA, Ho KJ. Bochdalek hernia of diaphragm in the adult: diagnosis by computed tomography. Chest. 1987;92:1098-101.

12. Wilbur AC, Gorodetsky A, Hibbeln JF. Imaging findings of adult Bochdalek hernias. Clin Imaging. 1994;18:224-9.

13. Willemse $P$, Schütte PR, Plaisier PW. Thoracoscopic repair of a Bochdalek hernia in an adult. Surg Endosc. 2003;17:162.

14. Rice GD, O'Boyle CJ, Watson DI, Devitt PG. Laparoscopic repair of Bochdalek hernia in an adult. ANZ J Surg. 2001;71:443-5.

15. Taskin M, Zengin K, Unal E, Eren D, Korman U. Laparoscopic repair of congenital diaphragmatic hernias. Surg Endosc. 2002;16:869.

16. Nakashima S, Watanabe A, Hashimoto M, Mishina T, Obama T, Higami T. Advantages of video-assisted thoracoscopic surgery for adult congenital hernia with severe adhesion: report of two cases. Ann Thorac Cardiovasc Surg. 2011;17:185-9.

17. Esmer D, Alvarez-Tostado J, Alfaro A, Carmona R, Salas M. Thoracoscopic and laparoscopic repair of complicated Bochdalek hernia in adult. Hernia. 2008; 12:307-9

18. Laaksonen E, Silvasti S, Hakala T. Right-sided Bochdalek hernia in an adult: a case report. J Med Case Rep. 2009;3:9291.

19. Kitano Y, Lally KP, Lally PA. Congenital Diaphragmatic Hernia Study Group. Late-presenting congenital diaphragmatic hernia. J Pediatr Surg. 2005:40:1839-43.

\section{Publisher's Note}

Springer Nature remains neutral with regard to jurisdictional claims in published maps and institutional affiliations.

\section{Submit your manuscript to a SpringerOpen ${ }^{\circ}$ journal and benefit from:}

- Convenient online submission

- Rigorous peer review

- Open access: articles freely available online

- High visibility within the field

- Retaining the copyright to your article

Submit your next manuscript at springeropen.com 